\title{
Mentally ill adults had fewer homeless days in staffed group homes than in independent flats
}

\author{
Goldfinger SM, Schutt RK, Tolomiczenko GS, et al. Housing placement and subsequent days homeless among formerly \\ homeless adults with mental illness. Psychiatr Serv 1999 May;50:674-9.
}

QUESTIONS: In homeless, mentally ill adults, does placement in a staffed group home reduce homelessness when compared with placement in an independent flat? Do individual characteristics predict homelessness?

\section{Design}

Randomised (unclear allocation concealment*), unblinded*, controlled trial with 18 months of follow up.

\section{Setting}

Boston, Massachusetts, USA.

\section{Patients}

118 adults (mean age 38 y, $72 \%$ men, $41 \%$ AfricanAmerican) who were homeless and mentally ill (45\% schizophrenia, 17\% schizoaffective disorder, $14 \%$ bipolar disorder, $13 \%$ major depression). $75 \%$ of participants also had lifetime secondary DSM-III-R axis I diagnoses (approximately 50\% alcohol or drug abuse). Exclusion criteria were absence of mental illness, lack of fluency in English, or unsuitability for independent living because of the risk of danger to self or others. Follow up was 93\%.

\section{Intervention}

Adults were allocated to staffed group housing $(\mathrm{n}=63)$ or independent flats run by the Boston Housing Authority $(\mathrm{n}=55)$. A voluntary weekly group was offered at the flat sites, but no other on site programming or clinical staff were available. 7 group homes each housed 6-10 tenants and 24 hour staffing was provided, although project staff encouraged residents to assume household decision making.

\section{Main outcome measures}

Number of days of homelessness over 18 months. A secondary outcome was housing status at the end of follow up.

\section{Main results}

Adults in group homes had fewer days of homelessness than adults in independent flats (mean number of homeless days $43 v 78, \mathrm{p}<0.05$ ). At 18 months, $76 \%$ of adults were in community housing with no difference in homelessness between groups. Independent predictors for homelessness were residence in an independent flat $(\mathrm{p}<0.05)$, minority ethnicity $(\mathrm{p}<0.05)$, lifetime substance abuse $(p<0.01)$, consumer preference for independent living $(\mathrm{p}<0.05)$, and clinicians' recommendation of group living for consumer $(\mathrm{p}<0.001)$

\section{Conclusions}

In homeless, mentally ill adults, residence in staffed group homes led to fewer days of homelessness than living in independent flats. Predictors for homelessness were type of residence, minority ethnicity, lifetime substance abuse, consumer preference for independent living, and clinicians' recommendation for group living for consumer.

*See glossary.

\section{COMMENTARY}

Throughout the industrialised world, recent decades have witnessed dramatic reductions in both the number and per capita ratios of people living in public mental hospitals. In the US, up to one third of all homeless people-more than 200000 people-suffer from serious mental illness. ${ }^{1}$ Homelessness and unavailable or inappropriate housing options pose serious problems for the effective administration of mental health services. ${ }^{2}$ Goldfinger $e t a l$ show that direct placement in either independent or supervised community residencies is an effective approach to homelessness for patients assessed as not imminently dangerous to themselves or others. The overall finding of fewer days of homelessness among those placed in group home settings compared with independent housing may be accounted for by a subset of randomised patients who are too disabled to manage fully independent housing. Comorbid substance abuse, commonly associated with medication non-compliance, ${ }^{3}$ emerges as the major clinical characteristic associated with better outcome in a supervised compared with independent placement. These data suggest that, at times, contrary to the client's stated preference for independent living, high risk individuals (including those with dual diagnosis and those judged by clinicians to need greater supervision) fare better in a supervised group home than in independent living situations.

Monitoring medication compliance and substance abuse that exacerbate illness are clearly 2 important functions of group home residential staff. Despite clinician recommendations some patients will reject group home placement. Other studies indicate that more intensive outreach services can produce better housing, clinical, and life satisfaction outcomes for patients residing in various settings. ${ }^{4}$

Wayne S Fenton, MD Chestnut Lodge Hospital Bethesda, Maryland, USA

1 Lehman AF, Cordray DS. Prevalence of alcohol, drug, and mental disorders among the homeless: one more time. Con temporary Drug Problems 1993;20:355-83.

2 Mechanic D, Rochefort DA. Deinstitutionalization: an appraisal of reform. Annual Review of Sociology 1990;16:301-

3 Fenton WS, Blyler CR, Heinssen RK. Determinants of medication compliance in schizophrenia: empirical and clinical findings. Schizophr Bull 1997;23:637-51.

4 Lehman AF, Dixon LB, Kernan E, et al. A randomized trial of assertive community treatment for homeless persons with severe mental illness. Arch Gen Psychiatry 1997;54:1038-43. 